\title{
CLIMATE CLASSIFICATION AND ITS APPLICABILITY TO BUILDINGS
}

\author{
JUAN JESÚS DE LA TORRE BAYO ${ }^{1}$, CARMEN DÍAZ-LÓPEZ ${ }^{1}$, MIGUEL LUIS RODRÍGUEZ GONZÁLEZ², \\ EMILIO MARTÍNEZ IBARRA ${ }^{3} \&$ MONTSERRAT ZAMORANO $^{1}$ \\ ${ }^{1}$ Department of Civil Engineering, University of Granada, Spain \\ ${ }^{2}$ Department of Applied Mathematics, University of Granada, Spain \\ ${ }^{3}$ Department of Regional Geographical Analysis and Physical Geography, University of Granada, Spain
}

\begin{abstract}
One of the main sectors responsible for the acceleration of climate change and the depletion of natural resources is the construction industry. This industry is responsible for using $40-50 \%$ of the Earth's energy and increasing the anthropogenic emissions of greenhouse gases. In this context, it is essential to study regional climates in order to foresee the adverse effects of construction and take the appropriate measures to avoid or minimise the damage that can be caused in the medium and long term. The balance between the climatic zones assigned to a region and the construction that be carried out there is fundamental. The proposed guidelines to obtain a potential classification could serve as a starting point for the bioclimatic design of buildings. To combat the heat island effect through building, it is considered viable to develop bioclimatic charts in the main cities of Spain to identify the possibilities of urban microclimates and to be able to combine these results with those obtained by climate severities. In order to adapt the climate classifications to the H2100, the proposal is to apply this methodology with the prediction data indicated by the Intergovernmental Panel on Climate Change, having, as a goal, the development of zoning that adapts to the climatic conditions.

Keywords: climate classification, urban heat island, green construction, H2100.
\end{abstract}

\section{INTRODUCTION}

Climate change is possibly the greatest environmental challenge of this century because of its global dimension and its profound social and economic impact. Scientific knowledge of its risks and impacts, combined with its monitoring and adaptation practices to address the problem, provides a basis to guide action aimed at reducing vulnerability and increasing the resilience in the face of climate change.

The unsustainability of the current production-consumption model [1], coupled with an increasing demand for energy throughout the world, has resulted in a significant increase in environmental impacts, such as the production of waste, water pollution, the depletion of the ozone layer and acidification of the atmosphere [2], as well as the depletion of natural resources and climate effects.

One of the main sectors of acceleration of climate change and the depletion of natural resources is the construction industry, which is responsible for $40-50 \%$ of all energy use on Earth, thereby increasing the anthropogenic emissions of greenhouse gases [3].

Consequently, construction can have a direct impact on the atmospheric conditions of a location. In this context, it is essential to know regional climates in order to foresee the adverse effects of construction and take the appropriate measures to avoid or minimise the damage that can be caused in the medium and long term [4].

It is vitally important to balance the climatic zones assigned to a given region and the construction that will take place, thereby prioritising the construction that adapts to the climatic conditions of the area, mitigates the adverse effects of climate change and has the potential to adapt to possible changes in the weather. 
Climatic classifications should be established as the basis for construction guidelines, directly relating climatic parameters with the characteristics of architectural design. In this relational context, comfort arises two thermal bonds as a link between meteorological conditions, the projects of construction and well-being the individual.

The use of a bioclimatic architecture applied to regions is specifically derived and zoned by studying the climate. This type of architecture should direct efforts towards the comfort of the people by taking advantage of the climatic elements of the environment in the best way possible, while at the same time mitigating any negative consequence that the construction could bring to the environment.

The main objective of this work is to analyse the main climatic classifications worldwide and at the national level, by prioritising classifications focused on architecture. After this study, it will be possible to propose the most important guidelines to develop a climate classification in Spain focused on construction.

\section{MATERIALS AND METHODOLOGY}

The work in question consists of a bibliographic review of the climatic condition classifications, mainly those that aim to improve the relationship between climate and construction through bioclimatic architecture. Considering that a bibliographic review is a type of scientific article, which, although not original, collects the most relevant information on a specific topic, following the research phases presented here.

\subsection{Topic approach and definition of objectives}

This project is developed around the climate, which is a very broad theme and practically unlimited. It is therefore of the utmost importance that the objectives are sufficiently clear. In this work, the difficulty lies in the depth and breadth of the bibliographic research to be carried out given the numerous studies related to the subject, both those developed from a quantitative as well as a qualitative perspective.

\subsection{Characterisation of information sources}

The first step is to pool information sources to research the knowledge required for the bibliographic compilation. In the case of this project, these came from digital databases of bibliographic data to printed books, conferences and publications on the web.

The research was carried out from a more general point of view to a more academic approach. It started by exploring the web content offered by the Google search engine in order to lay the foundations from the project, assimilate knowledge on the subject and the steps to follow in the realisation thereof. The next step was a more specific training focused on meeting the objectives; therefore, research was carried out into the various authors who have dealt with the same subject in order to compare the numerous ideas and to limit the search. The final step for the bibliographic compilation was researching scientific articles in relation to certain aspects of the subject.

The most used bibliographic databases were Science Direct, ResearchGate, Dialnet, Redalyc and Google Scholar. The books used have been provided by the library of the University of Granada. Other related data were obtained from publications of public bodies in Spain, such as the Ministry of Agriculture and Fisheries, Food and Environment (Ministerio de Agricultura y Pesca, Alimentación y Medio Ambiente, MAPAMA) or the State Meteorological Agency (Agencia Estatal de Meteorología, AEMET). 


\subsection{Bibliographic compilation process}

Two types of research are differentiated, one for the contextualisation of the work, information normally obtained from web pages or books, such as types of climatic classifications, and another for the revision of several versions of the same subject specific, such as a type of climate classification developed for two different countries. This information is more prevalent in scientific articles, for which a chain has been created with the consultation of the bibliography of work already carried out.

The bibliography was selected depending on the response level of the objectives of the work. Once the necessary information was chosen, it was classified in the same way as the structure of the project by encompassing it in different groups, coinciding with the blocks and sections included in the work's index.

\subsection{Drafting of project}

Finally, the work was drafted from the revised bibliography by contrasting information by several authors, as well as diversifying the origin of the results. This is a process by which one tries to give a response to the objectives set and draws general conclusions from the works.

\section{RESULTS}

Climatic classifications have been studied from ancient Greece to the present day, although there is no record of the first scientific classifications until the end of the 19th century when Koppen published a zoning based on temperature and precipitation, which is still used today as one of society's most accepted classifications of climatic conditions.

Over the years, classification models have evolved into methodology and applicability, adjusting to growing improvements in climate observation and the continuous social and economic changes in Earth's different regions.

The methods that follow the climatic classifications try to create relationships between climatological elements and their repercussion on the environment. They are made through the processing of the data by establishing various indices that seek to homogenise criteria that are used to establish zones with similar climatic characteristics.

The objectives of zoning are closely linked to the different forms of making use of the climate for social and economic purposes, justifying the importance of climatic classifications in the development of the vegetation, and consequently of agriculture, as an economic engine. This importance is extrapolated to the conditions of human life and social development, endowing the individual with knowledge of the climate in each region of the planet.

Spain's geographical situation gives the territory a remarkable variable climate due to its orographic characteristics, the continuous movement of atmospheric circulation and its position between two large bodies of water. These climatic factors generate a large difference in temperature and precipitation in different regions of the territory [5].

The importance of the development of climatic classifications in Spain as the ordering of the territory around the climate is key. Several of the zones implemented worldwide have been established in the country, which, along with other own models for Spain, scientifically show the climatic variety present, contrasted in the number of climatic types found within Spanish territory and the number of possibilities offered by certain classification methods.

By way of example, it can be seen that in the climate classification of Kottek et al. [6], there are 17 of the 20 types of climate put forward in the process in Spain, according to 
Thornthwaite [7] the number ascends to 8 of the 9 possibilities; whereas Rivas-Martínez and Armaiz [8] establishes 13 of the 24 climatic zones presented worldwide within Spanish territory.

In Spain, the applicability of most climatic classifications focuses on agroclimatic objectives. In a country characterised by scarce precipitation and high temperatures for the most part, in which agriculture is fundamental, the conservation of biodiversity is considered of special interest, as is the study of the territory to obtain agricultural resources.

As aforementioned, the purpose of the classifications of climatic conditions has evolved over time, being of special interest in recent years where methodologies focused on technical objectives and more specifically oriented to construction.

This change is mainly due to the need to combat the climate change produced in part by the construction and energy demand derived from this sector. The prediction models established by the Intergovernmental Panel on Climate Change (IPCC) establish climate change forecasts for the year 2100 for different potential scenarios, depending on its severity (H2100). In the Fifth Assessment Report (AR5), there is a wide variety of guidelines regarding climate change mitigation and adaptation strategies [9].

The current building model plays a very important role in this context marked by a high energy expenditure, which is further exacerbated in cities, where continued urbanisation has caused, along with other factors, the formation of so-called urban heat islands. This phenomenon is generally characterised by showing the effects of climate change in a more visible way in cities, and specifically an intense rise in temperature [10].

As a strategy to mitigate the adverse effects of the current climate situation, a change in the approach to construction is necessary, as well as the introduction of a bioclimatic or sustainable architecture model. This form of building focuses on the use of natural resources in improving the conditions of human comfort while integrating at construction in the natural environment from an energy saving perspective [11].

Bioclimatic classifications leading to the study of the relationship between climate and building conditions have developed across the planet, in many cases as an instrument used by governments to set guidelines for the architectural features of their respective territories [12].

Almost all of the methodologies used have the energy efficiency of buildings in common, relating the variables that most affect the architecture, temperature, solar radiation, relative humidity and air movements. The processes to develop the classifications, even with similar objectives, use different techniques depending on the availability of data or the extent of the surface to classify [13].

There are valid methods of calculating the building's energy performance using energy simulation, but they require too much climate information, which is sometimes not available [14]. The degrees-day is a simple technique that is accepted in many classifications, but it does not consider humidity or wind, so its accuracy is limited [15]. Bioclimatic charts are considered a very useful tool for the climate-human relationship, since they establish different comfort zones by building diagrams [16].

Due to the broad methodological possibilities to carry out a bioclimatic analysis, there is no conjunction in terms of the strategies to be followed by countries to carry out a climate classification focused on construction. Although they are unanimous in affirming the importance of the correct number of zones to characterise the territory with respect to any energy efficiency program, given that a number that is too low usually does not represent climatic variations, while a number that is too high can be very complicated in terms of construction guidelines [17]. 
In Spain, the Technical Building Codes (Código Técnico de la Edificación, CTE) belonging to the Ministry of Public Works and Transport, presents a classification of climatic zones at a national level focused on energy saving and which divides the territory into 13 climatic zones [18]. The methodology that was carried out was according to a defined variable for this particular zoning: climatic severity, which distinguishes between summer and winter conditions by analysing the demand for heating and air conditioning. The problem with this classification at the national level resides in its inaccuracy, since calculations are only made for 52 localities and the rest of the territory must extrapolate these data depending on its altitude.

At the regional level, there are also some bioclimatic classifications in Spain, such as those of Galicia [19] and the South Area of Madrid [20], which use Givoni's bioclimatic chart to establish zoning and develop building strategies. The EU-funded project for the bioclimatic characterisation of Extremadura [21] was carried out with the degrees-day methodology. By further analysing the Spanish territory, bioclimatic architecture design manuals can be found in which bioclimatic charts are generally made for the main cities, which have the most urbanisation indices.

Below are the maps of the communities of Galicia (Fig. 1) and Extremadura (Figs 2 and 3) according to their bioclimatic classification compared with the maps of the same communities that are generated with the CTE classification.

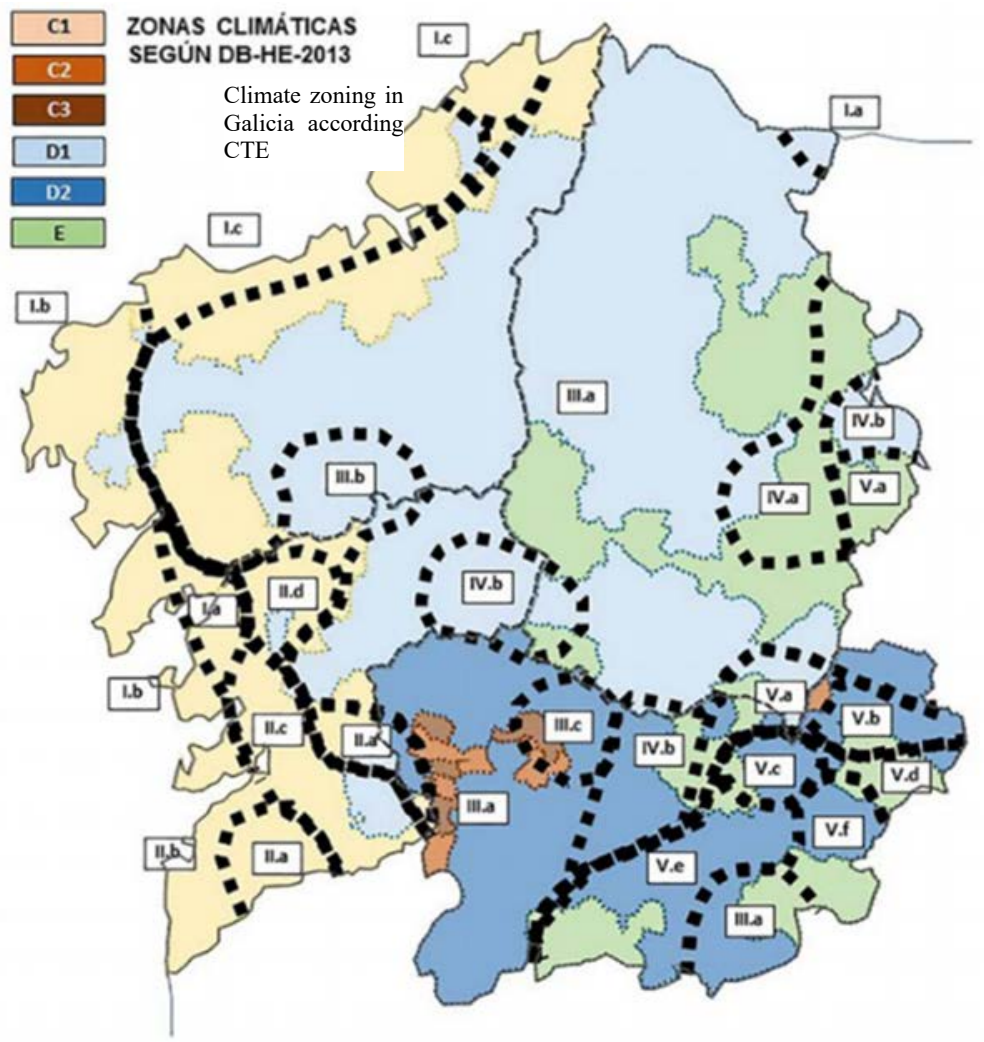

Figure 1: Comparison between the CTE classification and the classification bioclimatic for the community of Galicia [19]. 


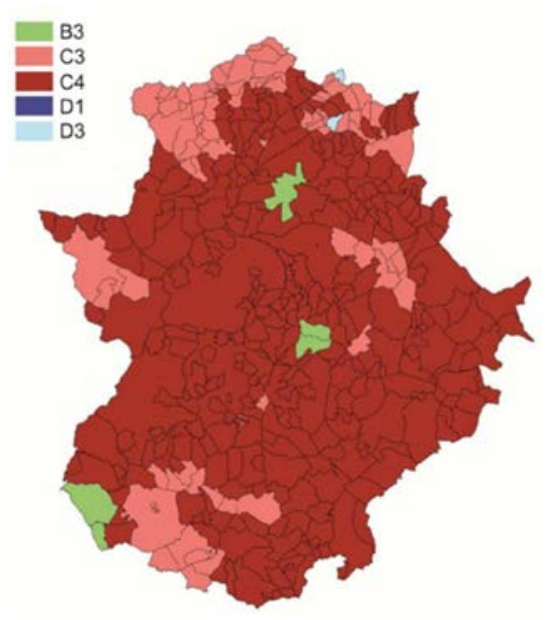

Figure 2: Representation of the climatic zones of Extremadura according to the bioclimatic classification [21].

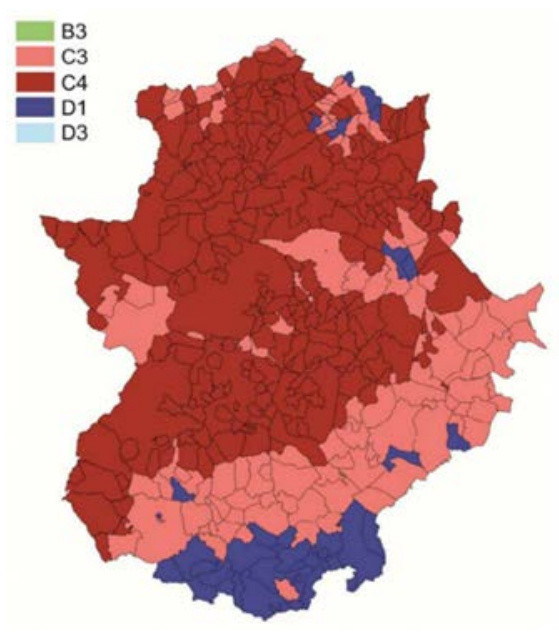

Figure 3: Representation of the climatic zones of Extremadura according to the CTE [21].

According to Da Casa Martin et al. [19], the zones established by the use of Givoni's bioclimatic chart in Galicia correspond to a situation that is closer to the actual climate compared with those established by the CTE (Fig. 1). The latter only considers the altitude for the extrapolation of data from cities, while the classification presented by the author considers more environmental conditions.

For the maps of Extremadura (Figs 2 and 3), it is concluded that using the degrees-day methodology, the climatic classification in the municipalities diverges significantly from the one carried out based on the CTE. This is because the CTE uses very few reference climates, so that for many municipalities of the community the interpolation of data is completed in reference to very distant weather conditions. 


\section{CONCLUSION}

As a result of the analysis of global and national level climate classifications, with a special focus on those aimed at construction, we present possible guidelines for a potential bioclimatic zoning in Spain. This is a classification that cannot only be considered for regulatory compliance and for the requirement of energy saving requirements, but also serves as a starting point for the bioclimatic design of buildings, including the impact of the heat island effect and being adaptable to the trends of the H2100 [22].

In Spain, climatic zoning is key depending on the season of the year; since there are large differences between summer and winter, the methodology must take into account climatic severity indices. Climatic data for the most important variables in construction must be obtained (temperature, radiation and humidity) for the maximum number of locations. For the municipalities where there is no record of these climatological data an interpolation should be made using the reference locations closest to them. Data interpolation, unlike the CTE classification, which only takes into account the altitude, should measure the distances with respect to latitude and also proximity to the sea, given the importance of these factors in climatic conditions, and consequently in construction. For locations without climatic records, the degrees-day method could also be used, which depends only on the temperature. These data could be contrasted with the results of the interpolation.

To combat the island heat effect through building, it is considered viable to develop bioclimatic charts in the main cities of Spain to identify the possibilities of urban microclimates and to be able to combine these results with obtained by climatic severities. In order to adapt the climatic classifications to the Horizon 2100, the use of the methodology with the prediction data that the IPCC has established, taking as an objective the development of zoning that is adapted to the climatic conditions.

\section{ACKNOWLEDGEMENT}

Supported by Biodiversity Foundation of the Ministry for the Ecological Transition.

\section{REFERENCES}

[1] Luthra, S., Govindan, K. \& Mangla, S.K., Structural model for sustainable consumption and production adoption: A grey-DEMATEL based approach. Resources, Conservation and Recycling, 125, pp. 198-207, 2017.

[2] Hu, M., Cunningham, P. \& Gilloran, S., Sustainable design rating system comparison using a life-cycle methodology. Building and Environment, 126, pp. 410-421, 2017.

[3] Hamdy, M., Carlucci, S., Hoes, P.J. \& M. Hensen, J.L., The impact of climate change on the overheating risk in dwellings: A Dutch case study. Building and Environment, 122, pp. 307-323, 2017.

[4] Macías, M. \& García Navarro, J., Metodología y herramienta VERDE para la evaluación de la sostenibilidad en edificios. Informes de la Construcción, 62(517), pp. 87-100, 2010.

[5] Capel Molina, J.J., Los climas de España, Oikus-tau: Barcelona, 1981.

[6] Kottek, M., Grieser, J., Beck, C., Rudolf, B. \& Rubel, F., World map of the KöppenGeiger climate classification updated. Meteorologische Zeitschrift, 15(3), pp. 259263, 2006.

[7] Thornthwaite, W.C., An approach toward a rational classification of climate. Geographical Review, 38(1), pp. 55-94, 1948.

[8] Rivas-Martínez, S. \& Armaiz, C., Bioclimatología y vegetación en la Península Ibérica. Bulletin de la Société Botanique de France. Actualités Botaniques, 131(2-4), pp. 110-120, 1984. 
[9] Fundación Biodiversidad, Cambio Climático: Bases Físicas. Guía Resumida del Quinto Informe de Evaluación del IPCC. Grupo de trabajo I, 2013. www.mapama.gob.es/es/cambio-climatico/temas/el-procesointernacional-de-luchacontra-el-cambio-climatico/guia_resumida_ar5-ipcc_tcm30-177777.pdf.

[10] Fernández Montes, S. \& Rodrigo, F.S., Cambio climático y cambio global. Asociación Española de Climatología (AEC) Serie A, n 9, 2014.

[11] Godoy, A., El confort térmico adaptativo. Aplicación en la edificación en España. Universidad Politécnica de Cataluña, Barcelona, España, 2012.

[12] Macías, M. \& García Navarro, J., Metodología y herramienta VERDE para la evaluación de la sostenibilidad en edificios. Informes de la Construcción, 62(517), pp. 87-100, 2010.

[13] Zhai, Z. \& Previtali, J.M., Ancient vernacular architecture: characteristics categorization and energy performance evaluation. Energy and Buildings, 42, pp. 357$365,2010$.

[14] Hensen, J.L.M., Simulation of Building Energy and Indoor Environmental Quality Some Weather Data Issues. Int. Work. Clim. Data Their Appl. Eng. 1-15 Prague, Czech Republic, 1999.

[15] Butche, K., Degree-Days: Theory and Application, CIBSE: London, 2006.

[16] Roriz, M., Ghisi, E. \& Lamberts, R., Bioclimatic zoning of Brazil: a proposal based on the Givoni and Mahoney methods. PLEA'99 Conference, 1999.

[17] Liu, F., Meyer, A.S. \& Hogan, J.F., Mainstreaming building energy efficiency codes in developing countries: Global experiences and lessons from early adopters. World Bank Working Paper, 204, 2010.

[18] Ministerio de Fomento, DB-HE CTE. Ahorro Energía, 2017. www.codigotecnico.org/ images/stories/pdf/ahorroEnergia/DBHE.pdf.

[19] Da Casa Martín, F., Echeverría Valiente, E.E. \& Celis D’Amico, F., Zonificación climática para su aplicación al diseño bioclimático. Aplicación en Galicia (España). Informes de la Construcción, 69(547), 2017.

[20] Da Casa, F., Adecuación bioclimática en la subregión de Madrid, para el diseño de los edificios y sus elementos constructivos. Universidad Politécnica de Madrid, Madrid, 2000 .

[21] Gobierno de Extremadura, Proyecto EDEA-Renov. D04.1_PROYECTO ClimEX, 2012.

http:/renov.proyectoedea.com/sites/default/files/action/D04.1_Geographicinformatio n-system-of-an-energy-map.pdf.

[22] Sánchez, F.J., Álvarez S., Molina, J.L. \& González, R., Climatic zoning and its application to Spanish building energy performance regulations. Energy and Buildings, 40, pp. 1984-1990, 2008. 